\title{
Pertumbuhan Publikasi IImiah Dosen di Maluku pada Portal SINTA tahun 2017 dan 2019
}

\author{
Jusuf Nikolas Anamofa \\ DOI: https://doi.org/10.36339/jaspt.v3i2.258
}

\begin{abstract}
This study aims to determine the growth of scientific publication of lecturers in Maluku at universities under the auspices of The Ministry of Education and Culture. The method used is a-comparative timeseries of 2017 research data compared with 2019 research data. The variables used are the number of lecturers recorded in the university database; the number of of lecturers registered as verified authors in the SINTA portal; the number of of publications indexed by Scopus, web of science, and google scholar; number of citations; and the number of journals from universities in Maluku registered on the SINTA portal. The results showed a significant increase in these variables even though some universities were experiencing stagnation.
\end{abstract}

Keywords: scientific publication performance, scientific publication growth, lecturer research productivity, lecturer in maluku, sinta portal

\begin{abstract}
Abstrak
Penelitian ini bertujuan untuk mengetahui pertumbuhan publikasi ilmiah para dosen di Maluku pada perguruan tinggi di bawah naungan Kementerian Pendidikan dan Kebudayaan. Metode yang digunakan adalah time series comparative terhadap data penelitian tahun 2017 yang dibandingkan dengan data penelitian tahun 2019. Variabel yang dibandingkan adalah jumlah dosen yang terdata dalam Pangkalan Data Pendidikan Tinggi, jumlah dosen yang terdaftar sebagai penulis terverifikasi pada portal SINTA, jumlah publikasi yang terindeks scopus, web of science, dan google scholar, jumlah sitasi, dan jumlah jurnal dari perguruan tinggi di Maluku yang terdaftar pada portal SINTA. Hasil penelitian menunjukkan peningkatan signifikan pada variabelvariabel tersebut meskipun beberapa PT mengalami stagnasi.
\end{abstract}

Kata Kunci: kinerja publikasi ilmiah, pertumbuhan publikasi ilmiah, produktifitas penelitian dosen, dosen di maluku, portal sinta

\section{PENDAHULUAN}

Kewajiban utama dosen sebagai tugas profesionalnya sebagaimana tercantum dalam Undang-Undang Nomor 14 tahun 2005 tentang Guru dan Dosen pasal 60 adalah

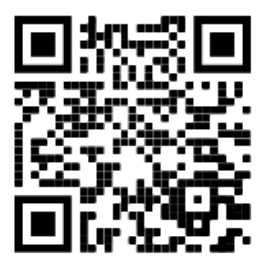

1. Program Studi Pendidikan Bahasa Indonesia STKIP Gotong Royong Masohi Indonesia EMail anamofajn@fdi.or.id

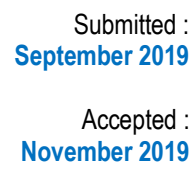

JAS-PT

JURNAL ANALISIS SISTEM PENDIDIKAN TINGG

ISSN $2580-5339$

eISSN $2620-5718$

Volume 3

Nomor 2

DESEMBER 2019

Hal $71-80$

FORUM DOSEN INDONESIA 
melaksanakan pendidikan, penelitian, dan pengabdian kepada masyarakat (Pemerintah RI, 2005). Dalam Pedoman Operasional Penilaian Angka Kredit Kenaikan Jabatan Akademik/Pangkat Dosen tahun 2019 ditetapkan distribusi kewajiban utama itu sesuai dengan jenjang jabatan akademik. Tugas melaksanakan penelitian harus lebih dari $25 \%$ untuk posisi asisten ahli dan meningkat seiring peningkatan jabatan akademik sampai harus lebih dari $45 \%$ untuk posisi guru besar. Bandingkan dengan tugas melaksanakan pendidikan yang harus lebih dari $55 \%$ untuk posisi asisten ahli dan menurun seiring peningkatan jabatan akademik yaitu harus lebih dari 35\% untuk posisi guru besar (Kemenristekdikti, 2019). Artinya, semakin meningkat level jabatan akademik seorang dosen, semakin besar tanggung jawabnya dalam melaksanakan penelitian. Aktifitas penelitian selalu dihubungkan dengan produktifitas penelitian yang ditunjukkan dengan penulisan dan publikasi hasil penelitian pada jurnal-jurnal ilmiah, sebagai bab dalam buku, atau disampaikan dalam konferensi-konferensi ilmiah nasional dan internasional kemudian diterbitkan dalam bentuk prosiding (lqbal, 2011).

Umumnya, penelitian dinyatakan selesai jika telah sampai pada tahap diseminasi berupa publikasi sebagai cara ilmuwan mengkomunikasikan pemikiran dan temuantemuannya kepada sejawat peneliti di bidangnya secara khusus dan masyarakat secara umum. Publikasi juga merupakan kontribusi peneliti secara teoretis dan praktis di dalam bidang kehidupan manusia. Dengan begitu, publikasi hasil penelitian dilihat tidak hanya dalam kepentingan mengejar kenaikan pangkat atau jabatan akademik sebagai bentuk karir sebagai seorang ilmuan semata (Dangal, Hamal, \& Giri, 2017; Day \& Gastel, 2016; McGuinness, 2015; Offutt, 2011). Publikasi adalah pusat aktifitas dari masyarakat ilmiah yang harus berdampak pada kemajuan ilmu, baik terkait dengan hasil, metode, standar, maupun prinsip-prinsip keilmuan (Cech, 2003). Peran publikasi ilmiah sebagai proses komunikasi ilmiah adalah peran sosial dalam rangka mendapatkan pengakuan dari disiplin ilmunya dengan cara membangun dan memelihara kekayaan intelektualnya. Peran berikutnya adalah peran arsip yaitu upaya mendokumentasikan karya ilmiah yang telah dievaluasi dan diterima oleh dunia ilmu pengetahuan. Peran yang terakhir adalah diseminasi dalam rangka menyebarluaskan gagasan ilmiah guna akumulasi ilmu pengetahuan (Tupan, 2015). Jika peneliti adalah guru atau dosen, maka publikasi ilmiah menjadi syarat utama kenaikan pangkat fungsional (Kemendikbud, 2016; Lukman, Ahmadi, Manalu, \& Hidayat, 2017). Dalam kenyataannya, belum semua dosen mempublikasikan hasil penelitian yang nampak dalam portal SINTA sebagai pusat pengindeks publikasi para peneliti Indonesia, termasuk dosen.

Penelitian tentang pertumbuhan publikasi para peneliti dunia pertama kali dikerjakan oleh Derek J. de Solla Price yang melakukan studi terkait publikasi para periode tahun 1650 sampai dengan 1950 (Larsen \& Ins, 2010). Khusus untuk para dosen di Provinsi Maluku, pada tahun 2017 telah dilakukan suatu studi terhadap publikasi ilmiah dosen di Maluku yang terindeks Scopus pada portal SINTA (Anamofa \& Nanuru, 2017). Studi tersebut dilakukan dengan menganalisis portal SINTA dan berhasil memetakan kinerja publikasi dosen pada Perguruan Tinggi (PT) di Maluku yang berada di bawah kendali Kementerian Riset, Teknologi, dan Pendidikan Tinggi. Pemetaan itu mesti dilakukan secara berkesinambungan agar diperoleh gambaran pertumbuhan kinerja publikasi para dosen. Karena itu, studi yang sama dilakukan pada tahun 2019.

JAS-PT eISSN $2620-5718$

Volume 3

Nomor 2

DESEMBER 2019

Hal $71-80$

FORUM DOSEN INDONESIA

Tujuan penelitian ini adalah untuk membandingkan temuan pada studi sejenis di tahun 2017 dengan kondisi pada tahun 2019 sehingga diketahui pertumbuhan kinerja publikasi. Variabelnya adalah perbandingan jumlah dosen yang terdata dalam Pangkalan Data Pendidikan Tinggi, jumlah dosen yang terdaftar sebagai penulis 
terverifikasi pada portal SINTA, jumlah publikasi yang terindeks scopus, web of science, dan google scholar, tipe publikasi terindeks scopus, jumlah sitasi terhadap publikasi dosen, dan jurnal dari perguruan tinggi di Maluku yang terdaftar pada portal SINTA.

\section{METODE PENELITIAN}

Penelitian ini bertujuan untuk membandingkan kinerja publikasi para dosen PT di Maluku yang berada di bawah Kementerian Riset, Teknologi dan Pendidikan Tinggi sebelum bergabung dengan Kementerian Pendidikan dan Kebudayaan pada tahun 2017 dan 2019. Metode yang digunakan adalah perbandingan antarwaktu yang sifatnya deskriptif (time series comparative) yaitu membandingkan variabel data yang sama di waktu berbeda. Data pertama berasal dari hasil studi tahun 2017 yang berjudul "Analysis of Scopus-Indexed Scientific Publication of Lecturers in Maluku on SINTA Portal" (Anamofa \& Nanuru, 2017). Data kedua berasal dari penelitian yang dilakukan pada bulan Oktober 2019. Khusus untuk portal SINTA yang selalu mengalami perubahan dalam hitungan jam, maka pengumpulan data pada penelitian kedua dilakukan pada tanggal 19 Oktober 2019 pukul 08.00 AM. Jika data tentang jumlah dosen pada penelitian tahun 2017 diambil langsung dari portal PDDikti, maka data jumlah dosen yang terdaftar di PDDikti pada penelitian tahun 2019 langsung diambil dari portal SINTA yang telah menyediakannya. Data-data tersebut kemudian dibandingkan berdasarkan afiliasi kelembagaan, jumlah penulis terverifikasi, jumlah publikasi terindeks, jumlah sitasi, dan jumlah jurnal yang terdaftar pada portal SINTA.

\section{HASIL DAN PEMBAHASAN}

Perguruan Tinggi di Maluku yang berafiliasi ke Kemenristekdikti pada tahun 2017 dan tahun 2019 jumlahnya tidak berubah yaitu sebanyak 30, terdiri atas 3 Perguruan Tinggi Negeri (10\%) dan 27 Perguruan Tinggi Swasta (90\%). Dari 30 Perguruan Tinggi tersebut, data pada tahun 2017 dan 2019 menunjukkan 29 Perguruan Tinggi (97\%) telah terdaftar di SINTA dan 1 Perguruan Tinggi (3\%) yaitu STKIP Hunimua belum terdaftar.

Tabel 1 menunjukkan peningkatan jumlah dosen yang terdaftar pada PDDikti tahun 2019 sebesar $28 \%$ dari tahun 2017 . Hal itu dapat menunjukkan ada rekrutmen dosen baru, juga ada penambahan data dosen pada PDDikti oleh operator tiap PT. Dosen yang terverifikasi sebagai penulis dalam portal SINTA pada tahun 2019 meningkat $251 \%$ dari tahun 2017. Peningkatan itu terjadi sejak masing-masing PT di Maluku memiliki verifikator SINTA yang dapat melakukan verifikasi langsung di tingkat PT terhadap para dosen yang melakukan registrasi di SINTA. Para verifikator SINTA di Maluku dilatih oleh Direktorat Riset dan Pengabdian Masyarakat, Direktorat Jenderal Penguatan Riset dan Pengembangan, Kementerian Riset, Teknologi dan Pendidikan Tinggi pada tanggal 17 April 2018 di Ambon. Jika dibandingkan dengan total penulis terverifikasi secara nasional tahun 2019 yaitu 176.561 orang, maka jumlah dosen PT di Maluku hanyalah $0.70 \%$ saja.

Persentase dosen yang terverifikasi sebagai penulis pada portal SINTA di tahun 2017 sebesar $17 \%$ dari total jumlah dosen yang terdaftar pada PDDikti, sementara pada tahun 2019 sebesar 47\% dari total jumlah dosen. Memang terjadi kenaikan 30\% tetapi masih ada PT yang para dosennya sama sekali belum terverifikasi sebagai penulis pada portal SINTA sejak tahun 2017 yaitu STIA Abdul Azis Kataloka, STIS Mutiara, STISIP Kebangsaan, STIH Muhammad Thaha Tual, dan Akademi Kebidanan Aru.

JAS-PT

JURNAL ANALISIS SISTEM PENDIDIKAN TINGG ISSN $2580-5339$ elSSN $2620-5718$ Volume 3 Nomor 2 DESEMBER 2019 Hal $71-80$

FORUM DOSEN INDONESIA 
Terdapat beberapa PT yang jumlahnya kurang dari 10\%, ada yang antara 10\%-50\%, dan ada yang di atas $50 \%$, tetapi belum ada PT yang $100 \%$ dosennya telah terverifikasi sebagai penulis pada portal SINTA.

Tabel 1. Perbandingan Jumlah Dosen Terverifikasi dalam SINTA Tahun 2017 dan 2019

\begin{tabular}{|c|c|c|c|c|c|c|c|c|c|c|}
\hline \multirow{3}{*}{ No } & \multirow{3}{*}{$\begin{array}{c}\text { Afiliasi } \\
1 \\
\end{array}$} & \multicolumn{2}{|c|}{$\begin{array}{l}\text { Jumlah } \\
\text { Dosen }\end{array}$} & \multicolumn{2}{|c|}{$\begin{array}{c}\text { Dos. } \\
\text { Terverifikasi }\end{array}$} & \multicolumn{3}{|c|}{ Persentase } & \multicolumn{2}{|c|}{ Ranking SINTA } \\
\hline & & 2017 & 2019 & 2017 & 2019 & $4 / 2$ & $5 / 3$ & $7-6$ & 2017 & 2019 \\
\hline & & 2 & 3 & 4 & 5 & 6 & 7 & 8 & 9 & 10 \\
\hline 1 & Universitas Pattimura & 1.083 & 1130 & 264 & 643 & $24 \%$ & $57 \%$ & $33 \%$ & 36 & 70 \\
\hline \multirow[t]{2}{*}{2} & Universitas Darussalam & 122 & 201 & 12 & 54 & $10 \%$ & $27 \%$ & $17 \%$ & 435 & 876 \\
\hline & Ambon & & & & & & & & & \\
\hline 3 & Universitas Iqra Buru & 69 & 172 & 7 & 109 & $10 \%$ & $63 \%$ & $53 \%$ & 479 & 297 \\
\hline 4 & Politeknik Negeri Ambon & 246 & 299 & 37 & 140 & $15 \%$ & $47 \%$ & $32 \%$ & 664 & 611 \\
\hline 5 & Poltek Perikanan Negeri Tual & 87 & 95 & 15 & 67 & $17 \%$ & $71 \%$ & $53 \%$ & 666 & 727 \\
\hline \multirow[t]{2}{*}{6} & Universitas Kristen Indonesia & 127 & 167 & 10 & 90 & $8 \%$ & $54 \%$ & $46 \%$ & 870 & 652 \\
\hline & Maluku & & & & & & & & & \\
\hline 7 & Akademi Maritim Maluku & 24 & 30 & 1 & 3 & $4 \%$ & $10 \%$ & $6 \%$ & 873 & 1736 \\
\hline 8 & STIA Trinitas & 17 & 21 & 1 & 3 & $6 \%$ & $14 \%$ & $8 \%$ & 3.381 & 3566 \\
\hline 9 & STP Hatta-Sjahrir Banda & 17 & 19 & 0 & 7 & 0 & $37 \%$ & $37 \%$ & 3.382 & 1784 \\
\hline 10 & STIA Darul Rahman Tual & 12 & 0 & 0 & 1 & 0 & & & 3.383 & 3552 \\
\hline 11 & STIA Abdul Azis Kataloka & 23 & 24 & 0 & 0 & 0 & $0 \%$ & $0 \%$ & 3.384 & 4350 \\
\hline 12 & STIE Umel & 14 & 35 & 0 & 1 & 0 & $3 \%$ & $3 \%$ & 3.385 & 2105 \\
\hline 13 & STIS Mutiara & 14 & 0 & 0 & 0 & 0 & & & 3.386 & 3850 \\
\hline 14 & STIA Langgur & 8 & 36 & 0 & 1 & 0 & $3 \%$ & $3 \%$ & 3.387 & 3556 \\
\hline 15 & STISIP Kebangsaan & 23 & 23 & 0 & 0 & 0 & $0 \%$ & $0 \%$ & 3.388 & 3849 \\
\hline 16 & STIE Saumlaki & 15 & 52 & 0 & 16 & 0 & $31 \%$ & $31 \%$ & 3.389 & 1593 \\
\hline 17 & STKIP Gotong Royong & 24 & 46 & 1 & 21 & $4 \%$ & $46 \%$ & $41 \%$ & 3.391 & 1698 \\
\hline 18 & STIEM Rutu Nusa & 12 & 20 & 0 & 2 & 0 & $10 \%$ & $10 \%$ & 3.394 & 1668 \\
\hline 19 & STIA Said Perintah & 12 & 47 & 0 & 1 & 0 & $2 \%$ & $2 \%$ & 3.396 & 2085 \\
\hline 20 & STIA Saumlaki & 9 & 25 & 0 & 13 & 0 & $52 \%$ & $52 \%$ & 3.398 & 1760 \\
\hline 21 & STKIP Hatta Sjahrir & 10 & 23 & 1 & 12 & $10 \%$ & $52 \%$ & $42 \%$ & 3.400 & 1513 \\
\hline 22 & STIKES Maluku Husada & 23 & 37 & 0 & 19 & 0 & $51 \%$ & $51 \%$ & 3.401 & 495 \\
\hline 23 & STIKES Pasapua Ambon & 12 & 25 & 0 & 15 & 0 & $60 \%$ & $60 \%$ & 3.402 & 1009 \\
\hline 24 & STIKOM Ambon & 21 & 26 & 1 & 3 & $5 \%$ & $12 \%$ & $7 \%$ & 3.403 & 3805 \\
\hline 25 & STKIP Saumlaki & 11 & 14 & 0 & 7 & 0 & $50 \%$ & $50 \%$ & 3.404 & 2140 \\
\hline 26 & STIH Muhammad Thaha Tual & 8 & 0 & 0 & 0 & 0 & & & 3.405 & 3749 \\
\hline 27 & STKIP Ita Wotu Nusa & 11 & 48 & 0 & 3 & 0 & $6 \%$ & $6 \%$ & 3.406 & 4586 \\
\hline 28 & Akademi Kebidanan Aru & 5 & 16 & 0 & 0 & 0 & $0 \%$ & $0 \%$ & 3.409 & 2375 \\
\hline \multirow[t]{2}{*}{29} & Akper Rumkit Tk. III & 10 & 9 & 2 & 6 & $20 \%$ & $67 \%$ & $47 \%$ & 3.411 & 1563 \\
\hline & Latumetten & & & & & & & & & \\
\hline Total & & 2069 & 2640 & 352 & 1237 & $17 \%$ & $47 \%$ & $30 \%$ & & \\
\hline
\end{tabular}

JAS-PT

ISSN $2580-5339$

eISSN $2620-5718$ Volume 3

Nomor 2

DESEMBER 2019

Hal $71-80$

FORUM DOSEN INDONESIA
Tabel 1 dan 2 disusun berdasarkan urutan ranking SINTA secara nasional. Terdapat perubahan yang signifikan terkait naik turunnya ranking SINTA Nasional. Dari 29 PT di Maluku, sebanyak 13 PT (45\%) mengalami penurunan ranking SINTA dan 16 PT (55\%) yang meningkat. Naik turunnya ranking SINTA secara nasional ditentukan oleh skor SINTA sepanjang waktu. Skor SINTA terdiri atas skor individu dan skor institusi. Skor individu ditentukan oleh jumlah dokumen artikel jurnal terindeks Scopus yang penilaiannya terbagi berdasarkan quartile atau peringkat suatu jurnal. Semakin kecil angka quartile suatu jurnal, semakin bereputasi jurnal tersebut. Selain itu, skor individu 
ditentukan juga oleh jumlah dokumen non-jurnal terindeks scopus, jumlah sitasi di scopus, jumlah sitasi di Google Scholar, dan jumlah artikel di jurnal terindeks SINTA yang penilaiannya terbagi berdasarkan peringkat jurnal menurut SINTA. Variabel yang menentukan skor institusi sama dengan variabel skor individu ditambah dengan skor terhadap jumlah jurnal terakreditasi yang terdaftar di portal SINTA dan peringkatnya ditentukan SINTA (Ristekdikti, 2019). Jumlah jurnal yang terdaftar pada portal SINTA dari Maluku adalah 8 jurnal oleh Universitas Pattimura dan 1 jurnal oleh Politeknik Negeri Ambon. Belum ada satupun jurnal dari PTS di Maluku yang mendapat peringkat dan terdaftar pada portal SINTA.

Tabel 2. Perbandingan Kinerja Publikasi Dosen dalam SINTA Tahun 2017 dan 2019

\begin{tabular}{|c|c|c|c|c|c|c|c|c|c|c|c|c|c|}
\hline \multirow[t]{2}{*}{ No } & \multirow[t]{2}{*}{ Afiliasi } & \multicolumn{2}{|c|}{ Dok. Scopus } & \multicolumn{2}{|c|}{ Sitasi Scopus } & \multicolumn{2}{|c|}{ Dokumen GS } & \multicolumn{2}{|c|}{ Sitasi GS } & \multicolumn{2}{|c|}{ Skor SINTA } & \multicolumn{2}{|c|}{ Ranking SINTA } \\
\hline & & 2017 & 2019 & 2017 & 2019 & 2017 & 2019 & 2017 & 2019 & 2017 & 2019 & 2017 & 2019 \\
\hline & 1 & 2 & 3 & 4 & 5 & 6 & 7 & 8 & 9 & 10 & 11 & 12 & 13 \\
\hline \multirow[t]{2}{*}{1} & Universitas Pattimura & 174 & 326 & 4.565 & 5.802 & 1.80 & 5.09 & 9.37 & 19.35 & 1.49 & 3.236 & 36 & 70 \\
\hline & & & & & & 5 & 5 & 4 & 1 & 4 & & & \\
\hline \multirow[t]{2}{*}{2} & Universitas Darussalam & 5 & 13 & 5 & 20 & 110 & 219 & 140 & 327 & 11 & 42 & 435 & 876 \\
\hline & Ambon & & & & & & & & & & & & \\
\hline 3 & Universitas Iqra Buru & 2 & 30 & 8 & 86 & 91 & 569 & 95 & 3.902 & 8 & 426 & 479 & 297 \\
\hline 4 & Politeknik Negeri Ambon & 1 & 26 & 0 & 88 & 120 & 541 & 50 & 759 & 2 & 103 & 664 & 611 \\
\hline \multirow[t]{2}{*}{5} & Politeknik Perikanan Negeri & 1 & 25 & 0 & 99 & 49 & 235 & 34 & 399 & 2 & 68 & 666 & 727 \\
\hline & Tual & & & & & & & & & & & & \\
\hline \multirow[t]{2}{*}{6} & Universitas Kristen Indonesia & 0 & 19 & 0 & 57 & 28 & 417 & 19 & 499 & 1 & 87 & 870 & 652 \\
\hline & Maluku & & & & & & & & & & & & \\
\hline 7 & Akademi Maritim Maluku & 2 & 2 & 2 & 3 & 10 & 11 & 5 & 12 & 1 & 3 & 873 & 1.736 \\
\hline 8 & STIA Trinitas & 0 & 0 & 0 & 0 & 10 & 14 & 2 & 4 & 0 & 0 & 3.381 & 3.566 \\
\hline 9 & STP Hatta-Sjahrir Banda & 0 & 0 & 0 & 0 & 0 & 17 & 0 & 33 & 0 & 3 & 3.382 & 1.784 \\
\hline 10 & STIA Darul Rahman Tual & 0 & 0 & 0 & 0 & 0 & 0 & 0 & 0 & 0 & 0 & 3.383 & 3.552 \\
\hline 11 & STIA Abdul Azis Kataloka & 0 & 0 & 0 & 0 & 0 & 0 & 0 & 0 & 0 & 0 & 3.384 & 4.350 \\
\hline 12 & STIE Umel & 0 & 0 & 0 & 0 & 0 & 2 & 0 & 12 & 0 & 1 & 3.385 & 2.105 \\
\hline 13 & STIS Mutiara & 0 & 0 & 0 & 0 & 0 & 0 & 0 & 0 & 0 & 0 & 3.386 & 3.850 \\
\hline 14 & STIA Langgur & 0 & 0 & 0 & 0 & 0 & 1 & 0 & 0 & 0 & 0 & 3.387 & 3.556 \\
\hline 15 & STISIP Kebangsaan & 0 & 0 & 0 & 0 & 0 & 0 & 0 & 0 & 0 & 0 & 3.388 & 3.849 \\
\hline 16 & STIE Saumlaki & 0 & 0 & 0 & 0 & 0 & 10 & 0 & 54 & 0 & 5 & 3.389 & 1.593 \\
\hline 17 & STKIP Gotong Royong & 0 & 1 & 0 & 7 & 6 & 47 & 0 & 20 & 0 & 4 & 3.391 & 1.698 \\
\hline 18 & STIEM Rutu Nusa & 0 & 0 & 0 & 0 & 0 & 12 & 0 & 42 & 0 & 4 & 3.394 & 1.668 \\
\hline 19 & STIA Said Perintah & 0 & 0 & 0 & 0 & 0 & 15 & 0 & 9 & 0 & 1 & 3.396 & 2.085 \\
\hline 20 & STIA Saumlaki & 0 & 0 & 0 & 0 & 0 & 14 & 0 & 31 & 0 & 3 & 3.398 & 1.760 \\
\hline 21 & STKIP Hatta Sjahrir & 0 & 1 & 0 & 12 & 6 & 41 & 2 & 40 & 0 & 7 & 3.400 & 1.513 \\
\hline 22 & STIKES Maluku Husada & 0 & 2 & 0 & 4 & 0 & 244 & 0 & 1.699 & 0 & 172 & 3.401 & 495 \\
\hline 23 & STIKES Pasapua Ambon & 0 & 0 & 0 & 0 & 0 & 72 & 0 & 285 & 0 & 29 & 3.402 & 1.009 \\
\hline 24 & STIKOM Ambon & 0 & 0 & 0 & 0 & 8 & 0 & 0 & 0 & 0 & 0 & 3.403 & 3.805 \\
\hline 25 & STKIP Saumlaki & 0 & 0 & 0 & 0 & 0 & 9 & 0 & 10 & 0 & 1 & 3.404 & 2.140 \\
\hline 26 & STIH Muhammad Thaha Tual & 0 & 0 & 0 & 0 & 0 & 0 & 0 & 0 & 0 & 0 & 3.405 & 3.749 \\
\hline 27 & STKIP Ita Wotu Nusa & 0 & 0 & 0 & 0 & 0 & 2 & 0 & 0 & 0 & 0 & 3.406 & 4.586 \\
\hline 28 & Akademi Kebidanan Aru & 0 & 0 & 0 & 0 & 0 & 0 & 0 & 0 & 0 & 0 & 3.409 & 2.375 \\
\hline \multirow[t]{4}{*}{29} & Akper Rumkit Tk. III & 0 & 1 & 0 & 8 & 6 & 14 & 0 & 33 & 0 & 5 & 3.411 & 1.563 \\
\hline & Latumetten & & & & & & & & & & & & \\
\hline & Total & 185 & 446 & 4.580 & 6.186 & 2.24 & 7.60 & 9.72 & 27.52 & & & & \\
\hline & & & & & & 9 & 1 & 1 & 1 & & & & \\
\hline
\end{tabular}

(Ket: GS = Google Scholar) 
Tabel 1 dan 2 disusun berdasarkan urutan ranking SINTA secara nasional. Terdapat perubahan yang signifikan terkait naik turunnya ranking SINTA Nasional. Dari 29 PT di Maluku, sebanyak 13 PT (45\%) mengalami penurunan ranking SINTA dan 16 PT (55\%) yang meningkat. Naik turunnya ranking SINTA secara nasional ditentukan oleh skor SINTA sepanjang waktu. Skor SINTA terdiri atas skor individu dan skor institusi. Skor individu ditentukan oleh jumlah dokumen artikel jurnal terindeks Scopus yang penilaiannya terbagi berdasarkan quartile atau peringkat suatu jurnal. Semakin kecil angka quartile suatu jurnal, semakin bereputasi jurnal tersebut. Selain itu, skor individu ditentukan juga oleh jumlah dokumen non-jurnal terindeks scopus, jumlah sitasi di scopus, jumlah sitasi di Google Scholar, dan jumlah artikel di jurnal terindeks SINTA yang penilaiannya terbagi berdasarkan peringkat jurnal menurut SINTA. Variabel yang menentukan skor institusi sama dengan variabel skor individu ditambah dengan skor terhadap jumlah jurnal terakreditasi yang terdaftar di portal SINTA dan peringkatnya ditentukan SINTA (Ristekdikti, 2019). Jumlah jurnal yang terdaftar pada portal SINTA dari Maluku adalah 8 jurnal oleh Universitas Pattimura dan 1 jurnal oleh Politeknik Negeri Ambon. Belum ada satupun jurnal dari PTS di Maluku yang mendapat peringkat dan terdaftar pada portal SINTA.

Dari persyaratan skor dan ranking SINTA tersebut, PTN yang meningkat peringkatnya hanyalah Politeknik Negeri Ambon, sementara Universitas Pattimura dan Politeknik Perikanan Negeri Tual mengalami penurunan peringkat. PTS yang meningkat peringkatnya adalah yang memiliki dokumen terindeks scopus. Peningkatan itu seiring dengan produktifitas penelitian yang sangat ditentukan oleh variabel individual dan institusi (Anamofa et al., 2018).

\section{Bagan 1: Perbandingan Jumlah Publikasi Terindeks Scopus PT di Maluku}

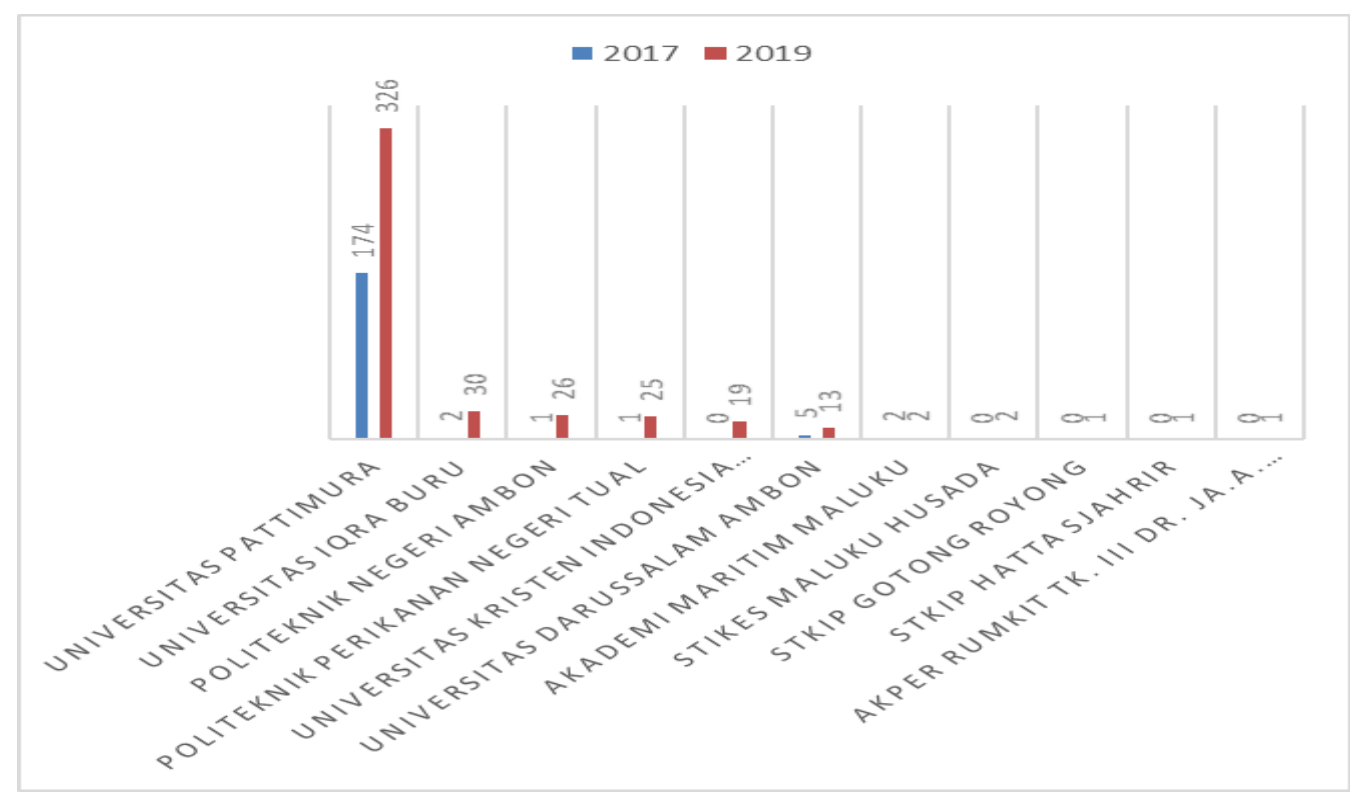

JAS-PT

JURNAL ANALISIS SISTEM PENDIDIKAN TINGGI ISSN $2580-5339$ elSSN $2620-5718$

Volume 3

Nomor 2

DESEMBER 2019

Hal $71-80$

FORUM DOSEN INDONESIA
Jumlah publikasi terindeks Scopus meningkat sebesar 141\%, dari 185 di tahun 2017 menjadi 446 di tahun 2019. Peningkatan itu dihasilkan oleh 11 PT (38\%) di tahun 2019 dimana sebelumnya pada tahun 2017 hanya oleh 6 PT (21\%) saja. Persentase terbesar publikasi terindeks Scopus disumbangkan oleh Universitas Pattimura, yaitu sebesar 73\%. Jumlah 446 publikasi terindeks Scopus oleh para dosen di Maluku itu hanya sebesar $0.71 \%$ dari total publikasi terindeks Scopus secara nasional.

Adapun jumlah publikasi yang terindeks Google Scholar (GS) di tahun 2019 mengalami peningkatan sebesar 238\% dari tahun 2017. Jumlah PT yang memiliki dokumen 
terindeks GS meningkat pada tahun 2019 sebesar 76\%. Dari data itu, nampak bahwa ada 7 PT (24\%) yang belum memiliki dokumen terindeks GS yaitu STIA Darul Rahman Tual, STIA Abdul Azis Kataloka, STIS Mutiara, STISIP Kebangsaan, STIKOM Ambon, STIH Muhammad Thaha Tual, dan Akademi Kebidanan Aru. Untuk 5 PT yang belum memiliki dosen terverifikasi di SINTA sangat wajar jika belum ada dokumen yang terindeks GS, tetapi yang patut diperhatikan adalah 2 PT yang sudah memiliki dosen terverifikasi di SINTA namun tidak memiliki dokumen GS yaitu STIA Darul Rahman Tual dan STIKOM Ambon. Jumlah dokumen terindeks GS para dosen di Maluku pada tahun 2019 sebesar 3\% dari total dokumen terindeks GS di SINTA, mengalami peningkatan dari tahun 2017 sebesar 1\%.

Tabel 3 Jumlah Publikasi Pada Jurnal Berdasarkan Peringkat Scopus, SINTA, dan WoS Tahun 2019

\begin{tabular}{|c|c|c|c|c|c|c|c|c|c|c|c|c|c|c|}
\hline \multirow{2}{*}{ No } & \multirow{2}{*}{ Nama PT } & \multicolumn{5}{|c|}{ Q Scopus } & \multicolumn{7}{|c|}{ Publ. Akrd. SINTA } & \multirow{2}{*}{ WoS } \\
\hline & & Q1 & Q2 & Q3 & Q4 & Und & S1 & S2 & S3 & S4 & S5 & S6 & Unc & \\
\hline 1 & Universitas Pattimura & 86 & 42 & 84 & 26 & 88 & 1 & 20 & 57 & 56 & 7 & 0 & 4994 & 104 \\
\hline 2 & Universitas Iqra Buru & 1 & 2 & 17 & 1 & 19 & 0 & 0 & 4 & 3 & 1 & 0 & 574 & 1 \\
\hline 3 & Politeknik Negeri Ambon & 0 & 4 & 9 & 1 & 12 & 0 & 0 & 1 & 1 & 19 & 0 & 520 & 2 \\
\hline 4 & Politeknik Perikanan Negeri Tual & 0 & 0 & 13 & 0 & 12 & 0 & 2 & 2 & 1 & 0 & 0 & 230 & 0 \\
\hline 5 & Univ. Kristen Indonesia Maluku & 0 & 0 & 8 & 0 & 11 & 2 & 3 & 1 & 4 & 0 & 0 & 407 & 0 \\
\hline 6 & Univ. Darussalam Ambon & 0 & 3 & 2 & 3 & 5 & 3 & 2 & 1 & 3 & 0 & 0 & 210 & 0 \\
\hline 7 & Akademi Maritim Maluku & 0 & 0 & 2 & 0 & 0 & 0 & 0 & 0 & 0 & 0 & 0 & 11 & 0 \\
\hline 8 & STIKES Maluku Husada & 0 & 0 & 0 & 2 & 0 & 0 & 0 & 0 & 1 & 0 & 0 & 243 & 0 \\
\hline 9 & STKIP Gotong Royong Masohi & 0 & 0 & 0 & 0 & 1 & 0 & 0 & 0 & 0 & 0 & 0 & 47 & 0 \\
\hline 10 & STKIP Hatta-Sjahrir Banda & 0 & 0 & 0 & 0 & 1 & 0 & 0 & 0 & 0 & 0 & 0 & 41 & 0 \\
\hline 11 & Akper Rumkit Tk III dr. JA Latumetten & 0 & 0 & 1 & 0 & 0 & 0 & 0 & 1 & 0 & 0 & 0 & 13 & 0 \\
\hline & Total & 87 & 51 & 136 & 33 & 149 & 6 & 27 & 67 & 69 & 27 & 0 & 7290 & 107 \\
\hline
\end{tabular}

Keterangan: $Q$ Scopus = Quartile Scopus; Und = undefined (tidak masuk kategori $Q$ Scopus tapi terindeks Scopus); Publ. Akrd. SINTA = Publikasi pada jurnal terakreditasi SINTA 1 s.d 6; Unc = Jurnal belum masuk kategori terakreditasi SINTA; WoS = Web of Science

Dari tabel 3, nampak bahwa kemampuan dosen di Maluku menembus jurnal-jurnal terindeks WoS masih sangat sedikit. Hal itu sejalan dengan gambaran yang disampaikan oleh Nanuru (Nanuru, 2018). Nampak pula bahwa jumlah publikasi dosen di Maluku pada jurnal-jurnal nasional berperingkat SINTA masih sangat sedikit dibandingkan jumlah dosen terverifikasi. Untuk jurnal peringkat SINTA 1 (S1) misalnya, hanya terdapat 6 artikel, sementara untuk S2 terdapat 27 artikel. Hanya ada 196 artikel dari para dosen di Maluku pada jurnal nasional berperingkat SINTA sampai dengan tahun 2019. Artikel-artikel itu disumbangkan oleh 8 PT di Maluku.

Tabel 4 menunjukkan bahwa jenis publikasi terindeks Scopus para dosen di Maluku sampai tahun 2019 yang paling banyak adalah artikel jurnal, diikuti artikel konferensi dan bab buku. Untuk bab buku, hanya disumbangkan oleh para dosen Universitas Pattimura.

Pada penelitian pertama dapat diketahui jumlah publikasi terindeks Scopus berdasarkan disiplin ilmu (subject coverage area) secara umum, tidak demikian halnya dengan data yang diambil dari portal SINTA tahun 2019 dimana subjects atau bidang keilmuan sudah sangat beragam dan masing-masing penulis terverifikasi sudah masuk dalam kategori bidang ilmunya. Bidang ilmu sebagai subjects dokumen yang tercatat di portal SINTA sebanyak 51.332 subjects. Namun, dari kecenderungan tahun ke tahun, bidang ilmu alam (natural sciences) peningkatan jumlah publikasinya sangat pesat

JAS-PT

JURNAL ANALISIS SISTEM PENDIDIKAN TINGGI ISSN $2580-5339$ eISSN $2620-5718$ Volume 3 Nomor 2

DESEMBER 2019 Hal $71-80$ 
dibandingkan dengan ilmu sosial, seni, dan humaniora (social sciences, arts, and humanities).

Tabel 4, Perbandingan Jumlah Publikasi Terindeks Scopus pada 11 PT Berdasarkan Jenis Publikasi

\begin{tabular}{|c|l|c|c|c|c|c|c|}
\hline \multirow{2}{*}{ No Nama PT } & \multicolumn{3}{|c|}{ Artikel Jurnal } & \multicolumn{2}{c|}{ Bab Buku } & \multicolumn{2}{c|}{$\begin{array}{c}\text { Artikel } \\
\text { Konferensi }\end{array}$} \\
\cline { 3 - 9 } & & $\mathbf{2 0 1 7}$ & $\mathbf{2 0 1 9}$ & $\mathbf{2 0 1 7}$ & $\mathbf{2 0 1 9}$ & $\mathbf{2 0 1 7}$ & $\mathbf{2 0 1 9}$ \\
\hline 1 & Universitas Pattimura & 157 & 261 & 5 & 8 & 12 & 57 \\
\hline 2 & Universitas Iqra Buru & 2 & 37 & 0 & 0 & 0 & 3 \\
\hline 3 & Politeknik Negeri Ambon & 1 & 15 & 0 & 0 & 0 & 11 \\
\hline 4 & Politeknik Perikanan Negeri Tual & 1 & 11 & 0 & 0 & 0 & 14 \\
\hline 5 & Univ. Kristen Indonesia Maluku & 0 & 11 & 0 & 0 & 0 & 8 \\
\hline 6 & Univ. Darussalam Ambon & 4 & 8 & 0 & 0 & 1 & 5 \\
\hline 7 & Akademi Maritim Maluku & 2 & 2 & 0 & 0 & 0 & 0 \\
\hline 8 & STIKES Maluku Husada & 0 & 2 & 0 & 0 & 0 & 0 \\
\hline 9 & STKIP Gotong Royong Masohi & 0 & 1 & 0 & 0 & 0 & 0 \\
\hline 10 & STKIP Hatta-Sjahrir Banda & 0 & 1 & 0 & 0 & 0 & 0 \\
\hline 11 & Akper Rumkit Tk III dr. JA Latumetten & 0 & 1 & 0 & 0 & 0 & 0 \\
\hline & & 167 & 350 & $\mathbf{5}$ & $\mathbf{8}$ & $\mathbf{1 3}$ & $\mathbf{9 8}$ \\
\hline
\end{tabular}

\section{PENUTUP}

Perbandingan temuan dari penelitian tahun 2017 dengan penelitian tahun 2019 menunjukkan pertumbuhan publikasi yang cukup signifikan pada sebagian besar PT di Maluku meskipun sebagian kecil PT belum menunjukkan hasil yang menggembirakan. Pertumbuhan itu dapat dilihat pada:

a. Jumlah dosen yang terdata pada PDDikti meningkat sebesar $28 \%$.

b. Jumlah dosen yang terverifikasi sebagai penulis dalam portal SINTA meningkat sebesar $251 \%$.

c. Jumlah publikasi terindeks Scopus meningkat sebesar $141 \%$.

d. Jumlah sitasi terindeks Scopus meningkat sebesar 35\%.

e. Jumlah publikasi terindeks Google Scholar meningkat sebesar $238 \%$.

f. Jumlah sitasi terindeks Google Scholar meningkat sebesar $185 \%$.

g. Telah terdata publikasi terindeks Web of Science.

h. Jumlah jurnal ilmiah yang masuk peringkat SINTA sebanyak 9 jurnal.

i. Terdapat 16 PT yang mengalami peningkatan peringkat SINTA secara nasional, terutama PTS di bawah kendali LLDikti Wilayah XII Maluku dan Maluku Utara.

Lepas dari pertumbuhan itu, beberapa hal yang tidak menunjukkan pertumbuhan, bahkan terjadi penurunan adalah:

a. Tidak ada satupun PT yang $100 \%$ dosennya terdaftar sebagai penulis terverifikasi pada portal SINTA.

JAS-PT

JURNAL ANALISIS SISTEM PENDIDIKAN TINGG

ISSN $2580-5339$

eISSN $2620-5718$

Volume 3

Nomor 2

DESEMBER 2019

Hal $71-80$

b. Terdapat 1 (satu) PT tidak terdaftar di portal SINTA sampai tahun 2019 yaitu STKIP Hunimua.

c. Terdapat 5 (lima) PT tidak memiliki dosen terverifikasi sebagai penulis di portal SINTA, yaitu STIA Abdul Azis Kataloka, STIS Mutiara, STISIP Kebangsaan, STIH Muhammad Thaha Tual, dan Akademi Kebidanan Aru. Seluruh PT itu berada di bawah kendali LLDikti Wilayah XII Maluku dan Maluku Utara. 
d. Masih ada PT yang para dosennya tidak memiliki publikasi terindeks Scopus, Google Scholar, dan WoS, terutama PTS di bawah kendali LLDikti Wilayah XII Maluku dan Maluku Utara.

e. Terdapat 13 PT yang mengalami penurunan peringkat SINTA secara nasional.

f. Belum ada satupun PTS yang jurnalnya masuk dalam pemeringkatan SINTA.

Berdasarkan apa yang dikemukakan di atas, peneliti merekomendasikan agar kepada PT yang kinerja publikasinya tidak bertumbuh atau lambat bertumbuh dilakukan pendampingan khusus oleh pihak LLDikti Wilayah XII dengan melibatkan sumberdaya yang ada di Maluku. Khusus kepada PTS yang belum memiliki penulis terverifikasi di SINTA agar dapat diperhatikan secara khusus dengan mendorong agar PT tersebut memiliki verifikator SINTA internal. Penelitian lanjutan dengan menggunakan metode perbandingan antar waktu (time series comparative) dapat dilakukan lagi pada tahun 2021 untuk mengetahui pertumbuhan publikasi para dosen pada PT di Maluku, terutama yang bernaung di bawah Kementerian Pendidikan dan Kebudayaan. Sasarannya dapat diperluas kepada PT di Maluku yang bernaung di bawah Kementerian Agama. Selain itu, penelitian juga dapat dilakukan untuk mengetahui latar belakang dan faktor-faktor yang mempengaruhi pertumbuhan kinerja publikasi para dosen pada PT di Maluku.

\section{DAFTAR PUSTAKA}

Anamofa, J. N., \& Nanuru, R. F. (2017). Analysis of Scopus-Indexed Scientific Publication of Lecturers in Maluku on SINTA Portal. Retrieved from https://www.researchgate.net/publication/332180274_Analysis_of_ScopusIndexed_Scientific_Publication_of_Lecturers_in_Maluku_on_SINTA_Portal

Anamofa, J. N., Nanuru, R. F., Suhardi, S., Lekahena, V., Dwi, T., Purimahua, S. Y., ... Hontong, S. A. (2018). Factors Influencing Research Productivity of Private Higher Education Institutions Lecturers in Kopertis Region XII Maluku and North Maluku Profile of Respondents (Vol. 2). Vol. 2. Retrieved from usuf_Anamofa2/publication/332202032/inline/jsViewer/5cab7b4da6fdcca26d079 76c?inViewer=1\&pdfJsDownload=1\&origin=publication_detail\&previewAsPdf=fal se

Cech, T. R. (2003). Sharing Publication-Related Data and Materials: Responsibilities of Authorship in The Life Sciences. https://doi.org/10.17226/10613

Dangal, G., Hamal, P. K., \& Giri, M. (2017). Understanding Research and Scientific Publication. Journal of Nepal Health Research Council, 15(1), 4-5.

Day, R. A., \& Gastel, B. (2016). Write and Publish a Scientific Paper (8th ed.). California: Greenwood.

Iqbal, M. Z. (2011). Factors Related to Low Research Productivity at Higher Education Level. Asian Social Science, 7(2), 188-193. Retrieved from http://www.ccsenet.org/journal/index.php/ass/article/download/9138/6697

Kemendikbud. (2016). Buku 4: Pedoman Kegiatan Pengembangan Keprofesian Berkelanjutan Bagi Guru Pembelajar. Kementerian Pendidikan dan Kebudayaan Direktorat Jenderal Guru dan Tenaga Kependidikan.

Kemenristekdikti. (2019). Pedoman Operasional Penilaian Angka Kredit Kenaikan Jabatan Akademik/Pangkat Dosen. Retrieved from http://ldikti12.ristekdikti.go.id/wp-content/uploads/2019/03/PO-PAK-

JAS-PT

JURNAL ANALISIS SISTEM PENDIDIKAN TINGG ISSN 2580 - 5339 eISSN $2620-5718$ Volume 3 Nomor 2 DESEMBER 2019 Hal $71-80$

FORUM DOSEN INDONESIA 
2019_MULAI-BERLAKU-APRIL-2019.pdf

Larsen, P. O., \& Ins, M. von. (2010). The rate of growth in scientific publication and the decline in coverage provided by Science Citation. Scientometrics, 84(3), 575603. https://doi.org/10.1007/s11192-010-0202-z

Lukman, Ahmadi, S. S., Manalu, W., \& Hidayat, D. S. (2017). Pedoman Publikasi IImiah. Jakarta: Direktorat Pengelolaan Kekayaan Intelektual Direktorat Jenderal Penguatan Riset dan Pengembangan Kementerian Riset, Teknologi, dan Pendidikan Tinggi.

McGuinness, W. (2015). The future of scientific thought. Journal of the Royal Society of New Zealand, 45(2), 95-100. https://doi.org/10.1080/03036758.2015.1013142

Nanuru, R. (2018). Menyikapi lemahnya geliat publikasi ilmiah di kopertis wilayah xii, maluku dan maluku utara. Buletin Dinamika Kopertis XII, (April).

Offutt, J. (2011). What Is the Purpose of Publishing? Retrieved from https://cs.gmu.edu/ offutt/stvr/21-4-October2011.html

Pemerintah RI. (2005). Undang-undang Republik Indonesia Nomor 14 Tahun 2005 tentang Guru dan Dosen. Produk Hukum, 54. Retrieved from http://luk.staff.ugm.ac.id/atur/UU14-2005GuruDosen.pdf

Ristekdikti. (2019). SINTA - Science and Technology Index. Retrieved December 14, 2017, from http://sinta2.ristekdikti.go.id/

Tupan. (2015). Analisis Karya IImiah Peneliti LIPI Pada Jurnal Internasional ScienceDirect. Visi Pustaka, 17(1), 20-32. Retrieved from http://dev.perpusnas.go.id/magazine/analisis-karya-ilmiah-peneliti-lipi-padajurnal-internasional-sciencedirect/

JAS-PT

JURNAL ANALISIS SISTEM PENDIDIKAN TINGG

ISSN $2580-5339$

eISSN $2620-5718$

Volume 3

Nomor 2

DESEMBER 2019

Hal $71-80$

FORUM DOSEN INDONESIA 